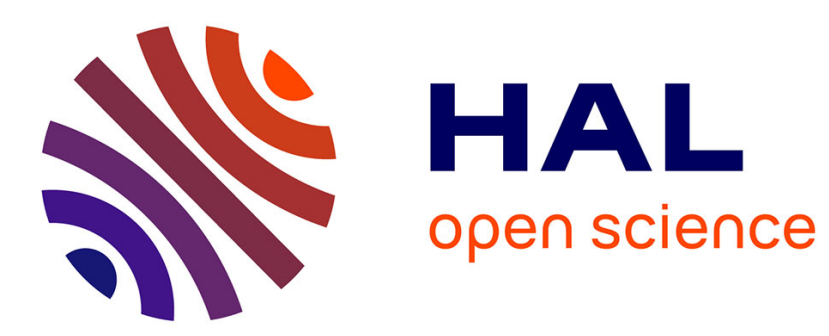

\title{
The upward bias of markups estimated from the price-based methodology
}

\author{
Hervé Boulhol
}

\section{To cite this version:}

Hervé Boulhol. The upward bias of markups estimated from the price-based methodology. 2005. halshs-00195883

\section{HAL Id: halshs-00195883 \\ https://shs.hal.science/halshs-00195883}

Submitted on 11 Dec 2007

HAL is a multi-disciplinary open access archive for the deposit and dissemination of scientific research documents, whether they are published or not. The documents may come from teaching and research institutions in France or abroad, or from public or private research centers.
L'archive ouverte pluridisciplinaire HAL, est destinée au dépôt et à la diffusion de documents scientifiques de niveau recherche, publiés ou non, émanant des établissements d'enseignement et de recherche français ou étrangers, des laboratoires publics ou privés. 

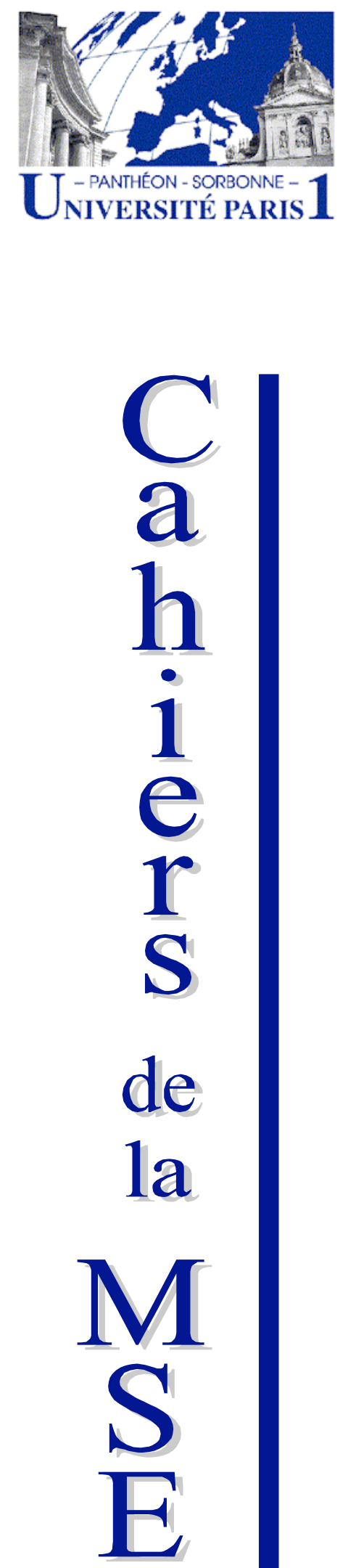

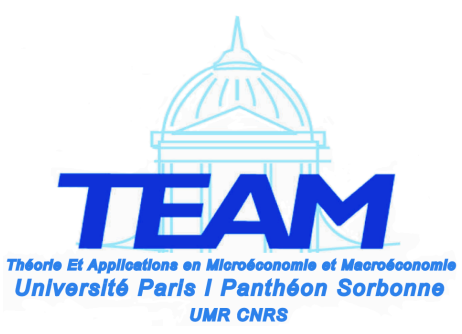

UMR CNRS

The upward bias of markups estimated from the price-based methodology

Hervé BOULHOL, IXIS-CIB \& TEAM

2005.55 


\title{
The Upward Bias of Markups Estimated from the Price-Based Methodology *
}

\author{
Hervé Boulhol \\ IXIS-CIB and TEAM (University Paris I Panthéon-Sorbonne and CNRS) \\ hboulhol@ixis-cib.com
}

July 2005

* I am grateful to Lionel Fontagné, Sébastien Jean and Joaquim Oliveira Martins for guidance and time. I would also like to thank David Galvin, Pamina Koenig and Daniel Mirza for their help, and the participants of the seminar at Delta, the OECD and Team for their remarks. 


\title{
Résumé
}

Des études précédentes ont souligné que la méthodologie développée par Roeger (1995) conduit à des markups trop élevés. Cette caractéristique est confirmée ici à partir des parts du capital implicites exagérément faibles. Théoriquement, le choix de normalisation, le faible ajustement du capital et les erreurs de mesure des services et du coût du capital entraînent chacun un biais à la hausse. Par exemple, le markup estimé selon cette méthodologie est en fait le markup ajusté par les rendements d'échelle associés aux facteurs variables seulement. Suivant l'analyse empirique, chacune de ces trois sources de surestimation semble jouer un rôle.

Mots clés: Markup, Fixité du capital, Concurrence imparfaite

\begin{abstract}
Previous studies have emphasized that Roeger's methodology generates too high markups. This feature is confirmed on the basis of the unrealistically low capital shares implied by the estimates herein. Theoretically, it is shown that the normalization choice, the slow adjustment of capital and the mismeasurement of capital expenditures, each produces an upward bias. For instance, the pricebased estimated markup is in fact the markup adjusted for returns to scale on the variable inputs only. Based on the empirical analysis, each of these three sources of overestimation is very likely to play a role.
\end{abstract}

Keywords: Markup, Capital Fixity, Imperfect Competition

JEL Classification: L11, L13, L60 


\section{Introduction}

Industrial economics is indebted to Hall (1986) for estimating markups at the sectoral levels. Improvements have then been proposed by Basu (1995), who highlights the quantitative importance of paying greater attention to materials, and by Roeger (1995), who derives a new methodology that circumvents intricate endogeneity issues in Hall's approach. The purpose of this study is to contribute to elucidating the puzzle raised by the too high level of markups estimated by Roeger's methodology, and noted in previous studies, including Hindriks, Nieuwenhuijsen and de Wit (2000) and Olivieira Martins (2002). The diagnosis of overestimation is made because the capital shares implied from the estimated markups are unrealistically low, often being even negative.

Normalization issue, capital quasi-fixity and measurement error of capital expenditures, each of these three elements is shown to bias Roeger-type markup upwards. Normalization choice is a well known issue in the cointegration literature. In a nutshell, estimating the Lerner index, from which the markup is deduced, or the markup directly makes a noticeable difference. The econometric relationship is such that the Roeger's original estimate of the Lerner index produces higher markups than its direct estimation.

However, even after accounting for the difference due to the choice of normalization, the puzzle, albeit attenuated, remains. The mismeasurement of the capital services and of the user cost are known to be a serious concern. Under fairly general assumptions, measurement error tends to bias Roeger's markup upwards. Indeed the change in capital expenditures appears on both sides of Roeger's equations and the coefficients applied to each side make the bias caused by mismeasurement an amplification bias.

Without downplaying the contribution of measurement error, the latter does not seem to be sufficient to explain the magnitude of the problem. Indeed, in most of the 129 OECD two-digit series in the sample, Roeger's estimated markup is not significantly different from the upper bound represented by the inverse of the sum of average labor and material shares in output. This stylized fact is consistent with the case of capital fixity. Indeed, when capital is purely fixed, Roeger's estimate does not lead to the 
markup over average cost (i.e. the markup over marginal cost if returns to scale are constant) but to markup over the cost of variable inputs. Therefore, markup to marginal cost will be overestimated to the extent that the returns to scale on the variable factors are decreasing. Although Roeger himself notes that "Hall's original method for estimating the markup does not require the use of capital costs and may therefore be more robust by allowing for cases in which capital is a true fixed factor of production", although the slow adjustment of capital is a widespread working hypothesis in both the theoretical and empirical literature, the quantitative impact of quasi-fixity on price-based markup measures has so far been either ignored or underestimated.

Overall, the three causes highlighted above are likely to combine and provide an explanation of the "anomaly" noted by Hindriks et al. The paper is organized as follows. Section 2 presents the primal approach due to Hall and the price-based or dual approach innovatively developed by Roeger. Section 3 addresses the normalization issue, whereas Section 4 treats the case of quasi-fixity. Section 5 assesses the impact of the mismeasurement of capital. Section 6 provides the empirical evidence and finally, Section 7 concludes

\section{Hall-type and Roeger-type regressions}

The common framework assumes a homogeneous production function:

$$
Y=A . F(K, L, M)
$$

where $Y$ is output, $K$ capital, $L$ labor, $M$ materials and $A$ a productivity term.

\subsection{Primal approach}

Noting $d z$ the logarithm differential of any given $Z$ variable and $e_{i}$ the elasticity of output with respect to factor $i$, differentiating (1) leads to:

$$
d y=e_{k} \cdot d k+e_{l} \cdot d l+e_{m} \cdot d m+d a
$$

$x$ denoting the returns to scale, Euler's equation can be expressed in terms of the elasticities: 


$$
e_{k}+e_{l}+e_{m}=x
$$

Substituting in (2) the elasticity of output to capital derived from (3) entails:

$$
d y=e_{l} \cdot(d l-d k)+e_{m} \cdot(d m-d k)+x \cdot d k+d a
$$

Finally, using the first order profit maximization conditions on the labor and material inputs, $e_{i}=\mu . a_{i}$ for $i=L, M$, establishes Hall-type specification, where $a_{i}$ denotes the share of factor $i$ in output and $\mu$ the markup to marginal cost:

$$
d y=\mu \cdot\left[a_{L} \cdot(d l-d k)+a_{M} \cdot(d m-d k)\right]+x \cdot d k+d a
$$

The important point is that equation (5) is established without assuming that the marginal revenue of capital equates its user cost. Therefore, Hall-type equation is valid even if capital is slow to adjust.

\subsection{Price-based or dual approach}

Conversely, the price-based approach requires that the first-order condition on capital apply, i.e. $e_{K}=\mu . a_{K}$. It follows from Euler's equation (3) that the factor shares are linked according to:

$$
a_{K}+a_{L}+a_{M}=x / \mu
$$

i.e. $\quad P . Y=v .(R \cdot K+W \cdot L+Q \cdot M)$

where $v \equiv \mu / x$ stands for the markup adjusted for returns to scale, $P$ being the price of output, and $R$, $W$ and $Q$ the factor prices. As shown by Oliveira Martins, Scarpetta and Pilat (1996), Roeger's specification can be obtained by differentiating (6b) and by using the capital share inferred from (6a):

$$
d p y-d r k=v \cdot\left[a_{L} \cdot(d w l-d r k)+a_{M} \cdot(d q m-d r k)\right] \quad \text { which is denoted } \quad d x=v \cdot d z
$$

with $d x$ and $d z$ being the respective LHS and RHS variables of equation (7). Roeger's equation links the markup to the sensitivity of the capital share to the changes of relative factor shares. In fact, Roeger estimates a specification equivalent to (7) but expressed in terms of the (adjusted) Lerner index $L=1-1 / v$ :

$$
(d x-d z)=L . d x
$$


What are the comparative advantages of each approach? On the one hand, the main difficulty in Hall's, and that Roeger's avoids, comes from the total factor productivity growth term, da, which is correlated to RHS variables in (5). Estimations should therefore turn to instrumental variables, but finding an efficient and valid instrument is a cumbersome task. Another advantage of Roeger's is that it only requires variables in value terms whereas Hall's needs outputs and materials in volume terms. Moreover, contrary to Hall's, Roeger's specification is unaffected whether the technological change is Harrod-neutral or biased against labor. On the other hand, Hall's methodology allows for the identification of both markup over marginal cost and returns to scale, whereas Roeger's can only estimate their ratio which is the markup over average cost. Moreover, Hall's does not need any computation of rental capital cost. Finally, for our purpose, the main disadvantage of Roeger's might be that, contrary to Hall's, the price-based specification is not robust to the case of capital fixity.

\section{Normalization issue}

The first reason why Roeger's markups could be biased upwards is linked to a well-known normalization issue in the cointegration analysis (see Hamilton, 1994, p.589). Roeger's methodology based on equation (8) assumes that the cointegrating vector $[(d x-d z), d x]$ is normalized to unity on the frst variable. This choice makes a material difference, the more the $\mathrm{R}^{2}$ is low. Indeed, let us compare Roeger's $v$ - based markup estimated from (7), $d x=v \cdot d z$, which we denote $\hat{v}$, to the original

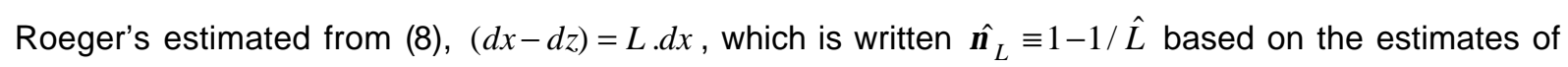
the Lerner index $\hat{L}$. We have the following relations based on OLS estimates without a constant term (in practice, adding a constant has no impact as it is not significant):

$$
\hat{L}=\frac{\sum d x_{t} \cdot\left(d x_{t}-d z_{t}\right)}{\sum d x_{t}{ }^{2}}=1-\frac{\sum d z_{t}{ }^{2}}{\sum d x_{t} \cdot d z_{t}} \cdot \frac{\left(\sum d x_{t} \cdot d z_{t}\right)^{2}}{\sum d x_{t}{ }^{2} \cdot \sum d z_{t}{ }^{2}}=1-\frac{R_{v}{ }^{2}}{\hat{v}}
$$

where $R_{v}{ }^{2}$ is the R-squared from (7). Consequently, it is easy to conclude that the original Roeger's estimates are higher than $v$ - based markups:

$$
\hat{v_{L}} \equiv \frac{1}{1-\hat{L}}=\frac{\hat{v}}{R_{v}^{2}} \Rightarrow \hat{v_{L}}>\hat{v}
$$


Even though, the fit is generally good with an average $R_{v}{ }^{2}$ of 0.98 across the 129 (country x sector) couples in the data described in Section 6, the average $L$-based markup stands at 1.147 versus 1.123 for the average $v$-based markup. ${ }^{1}$ It is important to realize that the convexity of the relation linking $\hat{v_{L}}$ to $\hat{L}$ has a very minor offsetting impact. Indeed a Taylor-development around $\hat{L}$ leads to: $E v_{L}=\hat{v}_{L}+\sigma^{2} / \hat{v}_{L}^{3}$, where $\sigma^{2}$ is the variance of $L$, and based on the estimates, the convexity impact $\sigma^{2} / \hat{v}_{L}^{3}$ averages a negligible 0.001 . This normalization issue highlights in fact the endogeneity of Roeger's RHS variable. This problem is also present in the $v$-based specification (7) because factor inputs are co-determined with output. However, from the spirit of the markup equation, whereby firms choose their price as a markup over cost, the specification (7) is likely to be preferred. In any case, a better answer is given by the approach proposed by Johansen (1988), which is beyond the scope of this study.

\section{Capital fixity in the price-based approach}

Equation (6b) $P Y=v \cdot \operatorname{COST}$ holds in fact for $\operatorname{COST}$ representing the total cost of the true variable factors used by frms to maximize profits. $\mathbf{t}$ is essential at this point to recall the markup equation comes from first order conditions and captures the idea of market power, i.e. the capacity firms have to mark up variable costs in setting their prices at the desired level. If capital is fixed, at least in the short run, then costs related to capital will be fixed costs. They will impact overall profitability but will disappear from the markup equation which becomes:

$$
P . Y=\mathrm{v}_{f i x} .(W . L+Q . M)
$$

Naturally in this case, the markup is adjusted for returns to scale on the variable factors only: $v_{f i x} \equiv \mu / x_{L M} \cdot{ }^{2}$ Differentiating equation (10) leads to Roeger's specification adapted to the case of capital fixity:

\footnotetext{
${ }^{1}$ Hindriks et al. were the first to note this hierarchy between $L$ - and $v$-based markups, without elucidating the relationship between the two measures. They concluded that $v$-based estimate is more reliable because of higher R-squared levels, which is not relevant, and also because it implies more reasonable capital shares, which is (see Section 6).

${ }^{2}$ Equation (10) is therefore strictly correct only if the production function is homogenous in the labor and material inputs. In the general case where $\theta \equiv\left(F_{L} L+F_{M} M\right) / F=x-F_{K} K / F$ is not constant, after some calculations, whether capital adjusts perfectly or not, one reaches: $d p y=\mu / \theta \cdot\left[a_{L} \cdot d w l+a_{M} \cdot d p_{m} m\right]-d \theta / \theta$.
} 


$$
d p y=v_{f i x} \cdot\left[a_{L} \cdot d w l+a_{M} \cdot d q m\right]
$$

Based on (10), (11) is equivalent to:

$$
d x=v_{f i x} . d z
$$

It is essential to note that this applies to the variables $d x$ and $d z$ defined in (7), i.e. including the capital expenditures. This is because the total coefficient on $d r k$ in (7) is $\left[1-v .\left(a_{L}+a_{M}\right)\right]$ which equals zero in the case of fixity. ${ }^{3}$ It is therefore immediately clear that, if capital is fixed, even in the short term, the estimate from Roeger's methodology will be $v_{f i x}$, i.e. the markup over total variable cost, and not the markup over average cost, $v$. This means that, in this case, Roeger's markup is in fact a measure of the so-called price-cost margin defined, as Schmalensee (1989, p.960) reminds us, as the difference between revenue and variable cost, i.e. the sum of labor and material expenditures, over revenue.

Therefore, even if total returns to scale are constant, Roeger's methodology overestimates markups to the extent that the returns to scale on the variable factors are decreasing. To make it very clear, consider the Cobb-Douglas case, $Y=K^{a} L^{b} M^{1-a-b}$. Roeger's estimates will then result in $\mu_{R}=\mu /(1-a)$, and even under perfect competition, Roeger's markups will be greater than unity.

\section{Measurement error in the price-based approach}

Before turning to the empirical evidence that the slow adjustment of capital biases Roeger's estimates upwards, let us consider an alternative explanation to the puzzle identified: measurement errors of capital services and user costs. Indeed, levels of capital services are difficult to measure and empirically identifying the role of capital in the production function has often proved to be an unfruitful quest. However, it is believed, and difficult to deny, that the growth rate of capital services is easier to grasp. Moreover, Burnside, Eichenbaum and Rebelo (1995) have shown that the cyclical behavior of capital services is underestimated, although the extent of this underestimation relies on the strong assumptions made, as stressed by the discussion following the paper.

\footnotetext{
${ }^{3}$ Based on footnote 2, this means that Roeger's and estimates for the case of capital fixity from (10) will only differ insofar as $\theta=x-F_{K} K / F$ varies with time and that these time changes are correlated with the RHS variable.
} 
Growth rates of capital variables, stock and user cost, are generally constructed by using a measure of the level as the denominator. There is then a serious inconsistency in putting forward a method based on variables expressed in changes, on the grounds that growth rates only can be used and, at the same time, to compute these series from series in levels. Indeed, Klette (1999, footnote 40) wonders about the advantage of estimating equation (8) rather than (6b) directly. ${ }^{4}$ Moreover, it is not so obvious that the imprecision has less impact on estimates based on methods using growth rates than on those using levels. In any case, the intent is not to focus on this argument. However, such a reasoning is much less convincing when applied to the user cost of capital. $\Delta R / R$ can indeed be extremely volatile, especially as $R$ is low (consider real interest rates during the oil crisis), and therefore there is little reason to believe that $\Delta R K / R K$ is better measured than $R K$.

The main objective in this section is to assess how measurement issues matter for the markup estimates based on the price-based approach. To separate the issues and because we think in terms of an alternative explanation, only the case of capital adjusting perfectly is considered.

Start from equation (7) $d x=v . d z$ where the RHS variable is observed with a measurement error due to the capital variable $d r k$, an asterisk indicating an unobserved true variable:

$$
d z=d z^{*}+u
$$

Classically, the error $u$ is assumed to be independent of $d z^{*}: E\left(u \cdot d z^{*}=0\right) \Rightarrow E(u \cdot d z)=E\left(u^{2}\right) \equiv \sigma_{u}^{2}$

Equation (12) implies that $d r k=d r k *-u /\left(a_{L}+a_{M}\right)$ and therefore the observed dependent variable is:

$$
d x=d x *+u /\left(a_{L}+a_{M}\right)
$$

The true relation $d x^{*}=v . d z^{*}+\varepsilon$ is now:

$$
d x=v \cdot d z+\left(\frac{1}{a_{L}+a_{M}}-v\right) u+\varepsilon
$$

Denoting $v_{f i x}=E\left(1 /\left(a_{L}+a_{M}\right)\right)$, the markup if capital were a fixed factor, and the residual $\zeta=1 /\left(a_{L}+a_{M}\right)-v_{f i x}$, equation (14) becomes:

\footnotetext{
${ }^{4}$ More generally and related to the general focus es here, Klette (1998) highlights that "From (6b) we can directly calculate the markup, given the assumptions maintained by Roeger that (i) constant returns to scale prevail, (ii) we can impute the rental costs for capital, and (iii) capital is fully adjusted to the rental costs" (p.7).
} 


$$
d x=v \cdot d z+(v f i x-v) \cdot u+\zeta \cdot u+\varepsilon
$$

By assuming that the error terms $\varepsilon$ and $\zeta$ are independent of $d z$, and noting $v_{R}$ Roeger's $v$-based markup, one gets:

$$
\operatorname{plim} v_{R}=v+\left(v_{f i x}-v\right) \theta
$$

$$
\text { where } \quad 0<\theta=\frac{\sigma_{u}^{2}}{\operatorname{plim}\left(d z^{*}\right)^{2}+\sigma_{u}^{2}}<1
$$

The impact of measurement error of the capital variables on Roeger's estimated markup is reflected by $\theta . v_{R}$ is unbiased only if $\theta=0$, but because $v_{f i x}$ is an upper bound to the true markup $v$ (due to capital expenditures), Roeger's markup is biased upwards and towards $v_{f i x}$. As $d r k$ is a component of the dependent variable (with coefficient -1: $d x \equiv d p y-d r k$ ), the measurement error bias turns out to be an amplification bias: $v<v_{R}<v_{\text {fix }}$.

In order, to establish the relation (15), the classical independence of the measurement error with $d z^{*}$ is critical. However, a less stringent assumption leads to a similar result. Indeed if, instead of $E(u \cdot d z)=E\left(u^{2}\right) \equiv \sigma_{u}^{2}$, the following reasonable inequalities apply: $E(u \cdot d z)>0$ and $E\left(d z d z^{*}\right)>0$, then the relation (15) holds with $0<\theta=E(u . d z) /\left(E(u . d z)+\left(E\left(d z . d z^{*}\right)\right)<1\right.$, with the same interpretation of $\theta$ as indicating the degree of measurement error.

\section{Empirical evidence}

Data for this study is from the OECD STAN database and is described in the Appendix. It covers twodigit industries of thirteen OECD countries between 1970 and 2000, that is 129 (country $x$ sector) series in total. The estimated $v$-based markup from equation $(7), \hat{v}_{R}$, will now be showed to overestimate markups adjusted for total returns to scale. Given the econometric relationships established in Section 3, this overestimation extends a fortiori to the original Roeger $L$-based markup from (8) due to the normalization issue. 


\subsection{Confirming that markups are too large in the price-based approach}

The estimated markup from the equation in level $(6 b)$ is denoted $\hat{v}_{\text {level }}$. Aside from any measurement issue, when capital adjusts perfectly, both $v_{R}$ and $v_{\text {level }}$ provide an unbiased estimate of the true markup $v$. Note that $\hat{v}_{\text {level }}$ is a weighted average of the observed markups $v_{t}=P R O D_{t} / \operatorname{COST}_{t}$ for time $t$. Indeed, it is straightforward that:

$$
\hat{v}_{\text {level }}=\frac{\sum \operatorname{COST}_{t} \cdot P R O D_{t}}{\sum \operatorname{COST}_{t}^{2}}=\sum \omega_{t} \cdot v_{t}, \text { where } \omega_{t}=\operatorname{COST}_{t}^{2} /\left(\sum \operatorname{COST}_{t}^{2}\right)
$$

Empirically, as $\hat{v}_{\text {level }}$ is very close to the (unweighted) average of the observed markups, the estimates will be compared to $\hat{v}_{\text {level }}$ only.

With US manufacturing sectors as an illustrative example, Table 1 shows that Roeger's estimates are much greater than the estimated $\hat{v}_{\text {level }}$, for which Durbin-Watson statistics indicate the need to correct for auto-correlation, although once done, the estimates do not change much. ${ }^{5}$ Roeger's markups are greater than the average level in 11 out of 14 sectors, being perceptibly lower in 1 sector only, and Roeger's average stands at 5.1 points above the average level.

As can be read from Table 2, this issue proves recalcitrant to very different assumptions for computation of capital data, referring to depreciation, interest rates and initial capital stock. ${ }^{6}$ Moreover, the capital share in total output, based on the favored computation of capital stock and rental cost the first one in table 2 used to produce table 1 -, varies from 3.6\% for "Leather products and footwear" to $9.8 \%$ for "Basic metals" on average over the period, mismeasurement is likely to account, only partially, for the magnitude of the problem.

Figure $1 \mathrm{~A}$ plots for each of the 129 (country $\mathrm{x}$ sector) couples the difference between ${\hat{v_{R}}}_{\text {and }} \hat{\mathrm{v}}_{\text {level }}$. This difference averages a high 7.8 points, the gap between the respective average of 1.123 and 1.045: in other words, margins calculated from the same series appear almost three times larger in the price-based approach. In Figure 1B, the (country $x$ sector) couples are sorted according to the size of

\footnotetext{
${ }^{5}$ Estimates are produced from an AR(2) process for the residuals, which corrects for auto-correlation successfully.

${ }^{6}$ I tested more extreme assumptions with a similar outcome overall.
} 
the difference. The latter is negative in eight cases only, and is in the $(0.025 ; 0.150)$ range for three quarters of the 129 sectors.

Obviously, it does not yet prove that the price-based approach markups are biased upwards. Indeed, if true capital stocks - Sub-section 6.4. extends the discussion around the notion of capital services - are only proportional and not equal to capital stocks, $\hat{v}_{\text {level }}$ will be biased. The important point is that $\hat{v}_{R}$ is just too high in absolute terms, as shown in the following, independent of the possibility that $\hat{v}_{\text {level }}$ underestimates the true markup.

The fact that Roeger-type markups seem too large has been highlighted by other studies based on different database. Among those studies, Hindriks et al. note that inferred capital shares from Roeger's estimates are unrealistically low as a large proportion run into negative territory. Table 3 compares effective capital shares with those inferred from $a_{K}=1 / \hat{v}-a_{L}-a_{M}$ and indicates the frequency of negative occurrences. Roeger's estimates lead to inferred capital shares very close to zero on average $(1.8 \%$ of output, against $6.1 \%$ in the data and $5.8 \%$ inferred from the equation in level, based on the first capital series) and negative for $43 \%$ of the 334 observations available for the USA. Note that these results are not very sensitive to the choice of the method for computing capital data, even though the two selected for illustration purposes - the first and third from table 2 - generate important variations in capital share measures. As these different studies rely on different computations of capital expenditures, this piece of evidence seems to support the fixity assumption rather than the measurement error assumption better.

\subsection{The case of capital fixity}

We now replicate the exercise above under the assumption of capital fixity, that is we compare $v_{R}^{f i x}$ from equation (11) to $v_{\text {level }}^{f i x}$ from equation (10). Figure 2A plots the difference in the two estimates for each series in a similar way to Figure $1 \mathrm{~A}$. Anticipating the formal testing in Sub-section 6.3., the difference between the two estimates is rarely significant and the average difference is -0.9 point. This reveals that the capital series create noise in the "perfectly adjusting" case. However, the extent of that noise suggests that mismeasurement is only part of the story. 
Indeed, it is noteworthy that $v_{R}$ and $v_{R}^{f i x}$ give on average the same estimates, 1.123 and 1.120 respectively, as displayed in Figure 2B. This means that, despite the fact that $v_{R}$ is not sensitive to capital stock series within a multiplicative factor, $d r k$ seems to play no role in the price-based markup.

As a result, the markup estimated under the fixity assumption from the equation in level, $\hat{v}_{\text {level }}^{f i x}$, is very close to Roeger's $v$ - based estimated markup, $\hat{v}_{R}$. Figure 3 plots the distribution of the difference across the 129 series. The average difference is a negligible -0.3 point and the absolute difference is lower than 2.5 points for $50 \%$ of the series, and lower than 5 points for $75 \%$. This is a strong result since $v_{\text {level }}^{f i x}$ represents an upper bound for any markup estimate, i.e. whatever the assumptions made. Consequently, it is also no surprise that Roeger's implied capital shares come out close to zero on average.

\subsection{Formal testing}

The first test bluntly assesses whether equation (10) makes more sense than equation (6b). From the following specification:

$$
P . Y=v \cdot(W \cdot L+Q \cdot M)+h v \cdot R \cdot K+u
$$

If the parameter $h$ is not significantly different from 0 then the assumption that capital is a quasi-fixed factor cannot be rejected. At the $95 \%$ (90\% respectively) confidence level, the parameter $h$, is significantly positive in only $23 \%$ ( $28 \%$ resp.) of the 129 sectors tested: stated differently, the fixity of capital cannot be rejected in $77 \%$ ( $72 \%$ resp.) of the cases. Moreover, this result is robust to various measures of capital stock and cost.

Table 4 and Figure 4 illustrate these results for the USA. Column 3 gives the average markup level in the case of capital fixity: as is apparent the systematic spread with Roeger's disappears. Then, the estimates of equation (17) are successively reported, first bounding $h$ between 0 and 1 , and lastly relaxing the constraints. On average, the $h$ parameter takes a value of 0.34 and 0.22 respectively and is almost never significantly different from 0 , suggesting a very low speed of capital adjustment to the optimal level. Moreover, the average difference between the unbounded estimate and Roeger's mostly vanishes, and the average absolute difference (not reported here) is more than halved. Supportively, it 
is remarkable that when the initial spread between Roeger's and level equation estimates (first two columns) is high, the capital fixity estimate, $\hat{v}_{\text {level }}^{f i x}$ in the third column, or the very similar unbounded version, brings markups closer towards Roeger's.

More importantly and more formally, the null hypothesis that the parameters $v_{\text {level }}, v_{R}, v_{\text {level }}^{f i x} \quad$ and $v_{R}^{f i x}$ estimated from equations (6B), (7), (10) and (11) respectively are equal is tested, and results are reported in Table 5. At the 5\% level, the equality $v_{\text {level }}=v_{R}$ is rejected for 78 of the 129 time series. The number of rejections falls to 18 in the fixity case $\left(H 0: v_{\text {level }}^{f i x}=v_{R}^{f i x}\right)$. More strikingly, the null hypothesis that Roeger's markup $v_{R}$ equals the upper bound $v_{\text {level }}^{f i x}$ is rejected in only 5 (15 respectively) sectors at the $1 \%$ level (10\% respectively). These results are strong evidence of both the fixity assumption and the overestimation of Roeger-type markups.

\subsection{Coming back on the mismeasurement of capital services}

One of the most convincing illustrations regarding the importance of properly measuring capital services, especially through the cycle, is provided by Shapiro (1993) and Burnside et al. In both cases, the idea is that true capital services, $K^{\star}$, should take into account the workweek of capital, $\Psi$, so that:

$$
K^{*}=\Psi . K
$$

which entails $d k^{*}=d \psi+d k$

This fits well within the framework developed in Section 4, with $u=\left(a_{L}+a_{M}\right) \cdot d \psi$, and is most likely to bias Roeger's estimate towards $v_{f i x}$, the extent of the bias depending on the correlation between $d \psi$ and $d z$. However, the bias ought not to be as large as given by $\theta$ in equation (16). The deep reason is that the approach relies on a price-based specification. The concept of the workweek of capital is perfectly designed for the measurement of total factor productivity. However, this will have an impact in Roeger-type equation only to the extent that additional usage of capital is more costly. In other words, the impact of the underestimation of the changes in capital services is attenuated as concerns the estimated price-based markup because $\left|d(r k)^{*}-d(r k)\right|<|d \psi|$. As Shapiro put it p.232: whether it has an impact "will depend on what the firm pays for increasing hours (of capital usage, my precision). 
[...] Simple calculations based on average shift premia suggest that the incremental cost of using capital at night is quite low. If this is the case, then the share of capital hours in cost would be low".

\section{Conclusion}

The purpose of this study was to understand why markups estimated by Roeger's methodology seem too high, as pointed out by other studies. Normalization, i.e. the choice of which variable is the dependent in the cointegrating relationship, was shown to be one of the reasons. However, this covers only a part of the problem. Additionally, the slow adjustment of capital and the mismeasuremement of capital expenditures both tend to bias price-based markups upwards.

Moreover, measurement error alone could hardly account for the magnitude of the overestimation, suggesting the three explanations combine. Finally, abstracting from mismeasurement, in the case of capital fixity, which finds strong empirical support, Roeger's estimation leads to the markup adjusted for returns to scale on the variable inputs only. Therefore, markup to marginal cost will be overestimated to the extent that returns to scale on the variable factors are decreasing, a much more likely possibility than the decreasing of the returns to scale on all production factors. This elucidates the puzzling outcomes of previous studies pointing at negative capital shares wrongly inferred from markup estimates. 


\section{Appendix: Data description}

Data covers thirteen OECD countries: Austria, Belgium, Canada, Denmark, Finland, France, Italy, Japan, Netherlands, Norway, Sweden, United Kingdom and United States. Two samples have been built covering manufacturing industries at the two-digit level for the period 1970-2000 (International Standard Industrial Classification (ISIC), third revision). One has more detailed information but is sparse, as some sectors are missing for a number of countries, and is composed of 138 time series (a country-sector crossing). The other contains more aggregated data but is more balanced with 129 annual time series available out of a total of 143. Sector identification is given in Table A1. Note that the averages across sectors presented in the following tables are unweighted, i.e. treating each equally, because our prime interest lies in the mechanisms at work rather than in the impact for the total economy.

Sectoral data come from the OECD Structural Analysis (STAN) Database. Table A1 details the 23 manufacturing sectors.

$\underline{\text { Variables }}$

PROD: Production (Gross Output) at current prices ( $P . Y$ in the text)

LABR: Labor compensation of employees (W.L in the text)

VALU: Value added at current prices.

VALUB: Value added at basic prices. When VALUB is available, $P . Y=P R O D-V A L U+V A L U B$.

Materials: $Q M=P R O D-V A L U$.

\section{$\underline{\text { Capital }}$}

The price of capital, $p_{k}$, used in the study is the price of investment calculated from the Gross Fixed Capital Formation at current prices (GFCF) and in volume (GFCFK). When data is not available, the price of the GDP deflator (source OECD Economic Outlook) is chosen for $p_{k}$. The user cost of capital is calculated classically according to: $R=p_{k} \cdot\left(r+d-\dot{p}_{k}{ }^{a}\right)$, where $r$ is the interest rate, $d$ the depreciation rate and $\dot{p}_{k}{ }^{a}$ is the expected relative change in the price of capital. By default, $r$ was chosen as the long-term interest rate (but an alternative with short-term rate was also tested), the depreciation was fixed at 0.05 (but 0.07 was also tested, see below) and $\dot{p}_{k}{ }^{a}$ was set at the average of the price change over the last three years. 
Net capital stock (NCAPK) is available directly in the data for Belgium and Italy only. For the other countries, I calculated the series based on the Gross Fixed Capital Formation in volume (GFCFK) according to: $K_{t}=(1-d) \cdot K_{t-1}+G F C F K_{t}$. Only, the starting point value for the net capital stock is missing to build the series. It was derived differently depending on the countries, due to data availability. For Austria, Finland, Japan, Norway and the USA, I used the Consumption of Fixed Capital (CFC) and inferred: $p_{k 0} \cdot K_{0}=C F C_{0} / d$ for the first date. For Canada, France, the UK, the Netherlands and Sweden, I computed $p_{k 0} \cdot K_{0}=\chi \cdot V A L U_{0} \cdot \theta \cdot \chi$ is the average, for each sector across countries for which the gross capital stock (CAPK) is available, of $p_{k} . C A P K / V A L U$ and is reported in table A2. The parameter $\theta$ reflects the ratio of net capital stock to gross capital stock. I ran simulations based on various methodologies (double-decline, geometric, hyperbolic, see OECD, 2001) and reasonable values of parameters to arrive at a ratio of between 0.50 and 0.85 . I chose $\theta=0.70$ by default, but compared the results with $\theta=0.55$. Finally, as Denmark provides gross capital stock only, I used the constant ratio $\theta$ to deduce net capital stock for all dates.

I shall now detail the various computations used for the case of the USA as they appear in Table 2. K1 was calculated, as described above, from the investment flows, a depreciation rate $d$ of 0.05 and an initial capital stock derived from $p_{k 0} \cdot K_{0}=C F C_{0} / d$. K2 was calculated similarly but using $d=0.07$. With the idea of testing extreme assumptions, $K 3$ was bluntly derived from $p_{k t} \cdot K_{t}=C F C_{t} / d$ for every date $t$ and $d=0.05$. K4 was calculated as $K 3$ but with $d=0.07$. I also tested as $r$, the average of the short-term and the long-term rates, and even a constant for the real interest rate. 


\section{References}

Basu S., 1995. 'Intermediate goods and business cycles: implications for productivity and welfare'. American Economic Review, 85, June, 512-531.

Burnside C., Eichenbaum M., Rebelo S., 1995. 'Capacity Utilization and Returns to Scale'. NBER Macroeconomics Annual, 67-124, Bernanke B.S. and Rotemberg J. J. (eds), MIT Press.

Hall R.E., 1986. 'Market structure and macroeconomic fluctuations'. Brooking Papers on Economic Activity 2, 285-322.

Hamilton J.D., 1994. Time Series Analysis. Princeton University Press.

Hindriks F., Nieuwenhuijsen H., de Wit G., 2000.'Comparative advantages in estimating markups'. EIM/SCALES ResearchReport, 0003/E.

Johansen S., 1988. 'Statistical Analysis of Cointegrating Vectors'. Journal of Economic Dynamics and Control, 12, 231-254.

Klette T.J., 1998. 'Market Power, Scale Economies and Productivity: Estimates from a Panel of Establishment Data'. Memorandum no. 15/98. Department of Economics, University of Oslo.

Klette T.J., 1999. 'Market Power, Scale Economies and Productivity: Estimates from a Panel of Establishment Data'. Journal of Industrial Economics, 4, 451-476.

OECD, 2001. Measuring capital. Available at www.oecd.org.

Oliveira Martins J., Scarpetta S., Pilat D., 1996. 'Mark-up ratios in manufacturing industries: estimates for 14 OECD countries'. OECD Working Paper, 162.

Oliveira Martins J., 2002. 'Mark-ups as an indicator of the degree of competition on product markets: an overview'. Mimeo.

Roeger W., 1995. 'Can imperfect competition explain the difference between primal and dual productivity measures? Estimates for U.S. manufacturing'. Journal of Political Economy, 103 (2), 316-330.

Schmalensee R., 1989. 'Inter-industry studies of structure and performance'. Handbook of International Organisation. Chapter 16, 951-1009.

Shapiro M.D., 1993. 'Cyclical Productivity and the Work week of Capital'. American Economic Review, Papers and Proceedings, 83 (2), 229-233. 
Figure 1A

Difference between Roeger-type Markup and (weighted) Average Markup Level*

$$
\hat{v}_{R}-\hat{v}_{\text {level }} \quad \text { (Equations 6b and 7) }
$$

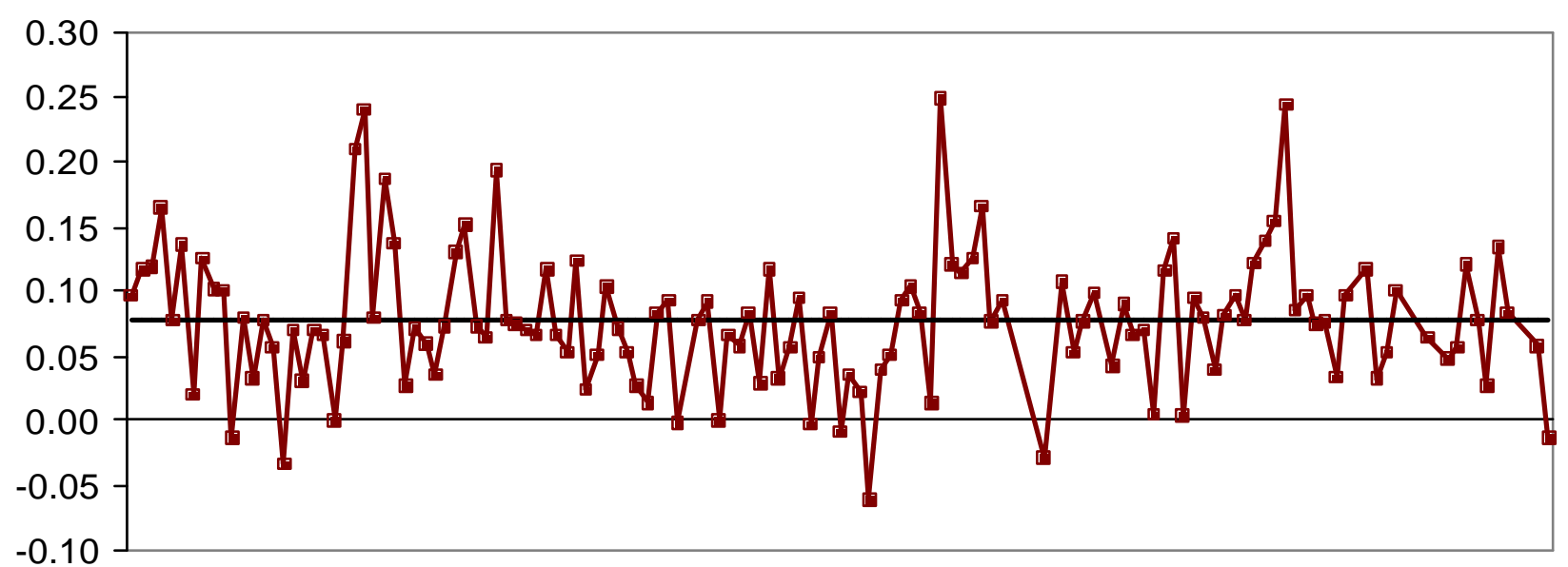

Average difference $\mathbf{=} \mathbf{0 . 0 7 8}$

$\left.{ }^{*}\right)$ : Each square represents one of the 129 (country $x$ sector) couples

Figure 1B

Distribution of the Difference between Roeger-type Markup

and (weighted) Average Markup Level, $\hat{v}_{R}-\hat{v}_{\text {level }}$

(\% of the 129 sectors)

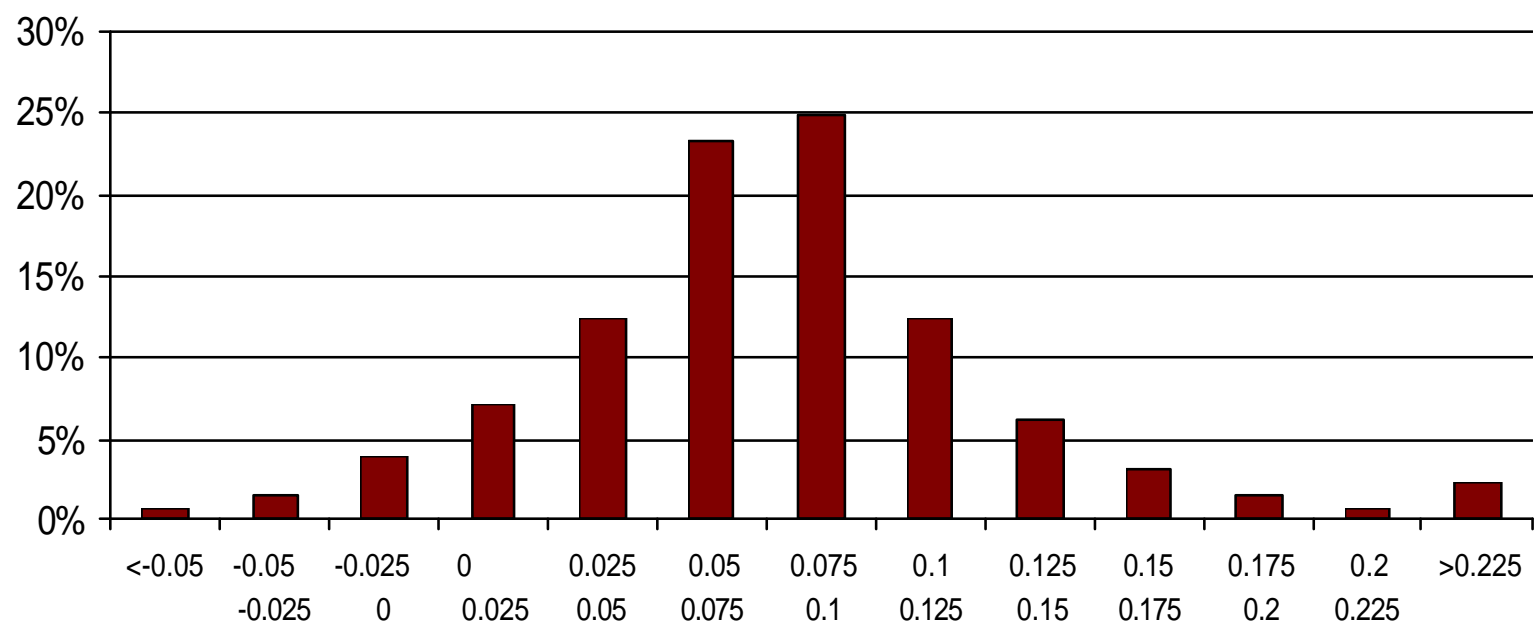

Difference between Roeger-type Markup and (weighted) Average Markup Level 
Figure 2A

Case of Capital Fixity

Difference between Roeger-type Markup and (weighted) Average Markup Level ${ }^{\star}$

$\hat{v}_{R}^{f i x}-\hat{v}_{\text {level }}^{f i x} \quad$ (Equations 10 and 11)

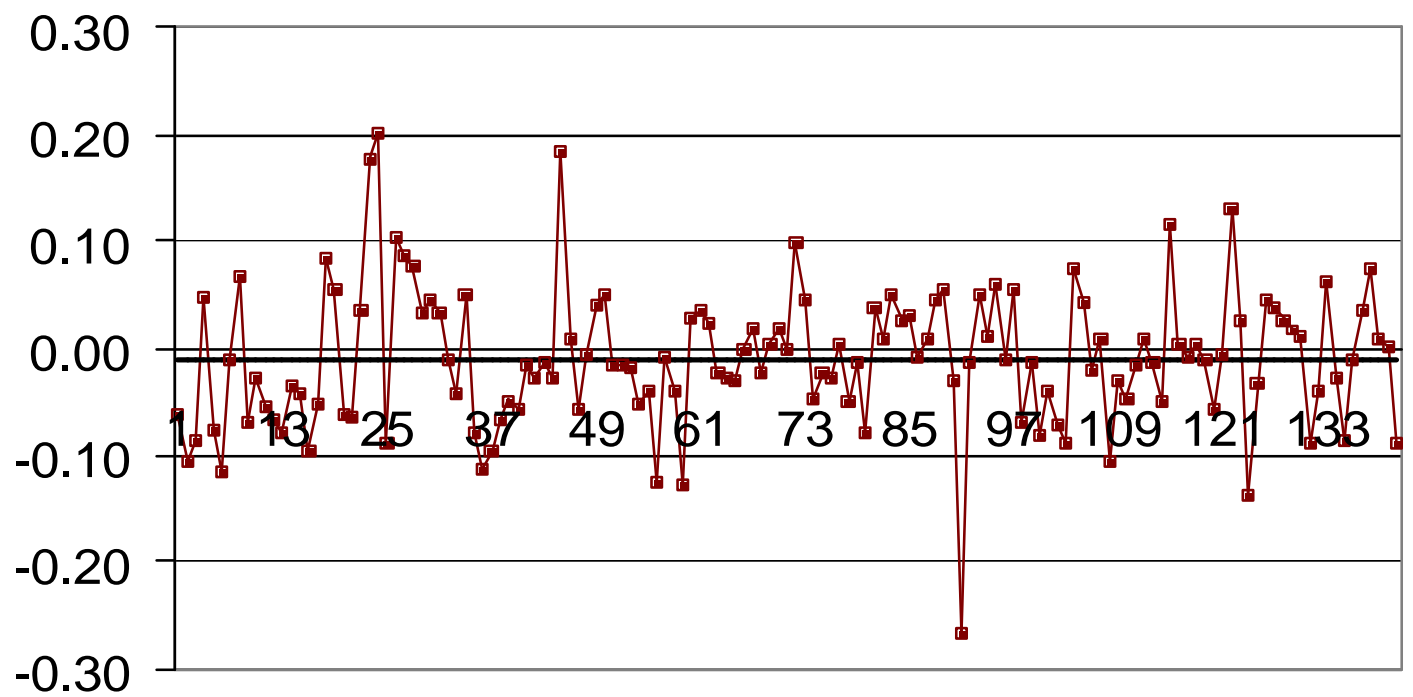

Average difference $=\mathbf{- 0 . 0 0 9}$

Figure 2B

Difference between Roeger-type Markups*

Perfectly adjusting case vs capital fixity case, $\hat{v}_{R}^{f i x}-\hat{v}_{R} \quad$ (Equations 7 and 11)

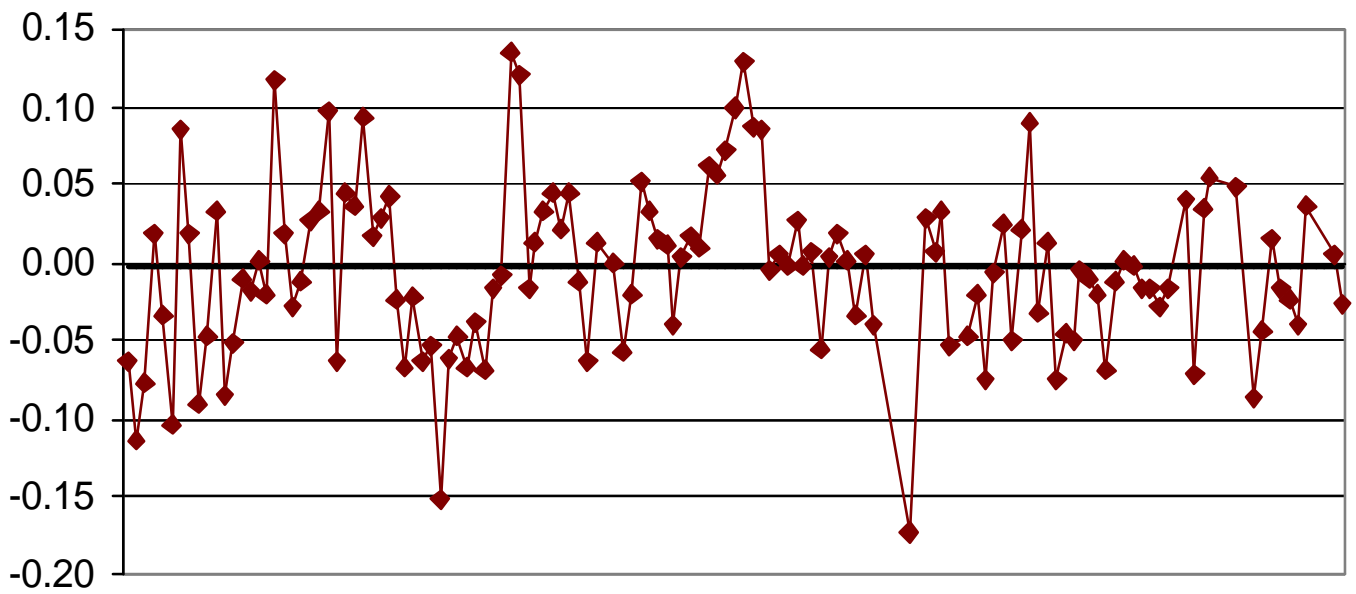

Average difference $=\mathbf{- 0 . 0 0 3}$

$\left(^{*}\right)$ : Each square represents one of the 129 (country $x$ sector) couples 
Figure 3

Distribution of the Difference between Roeger-type Markup and (weighted) Average Markup Level in the Fixity Case

$$
\hat{v}_{R}-\hat{v}_{\text {fix }}^{\text {level }}
$$

(\% of the 129 sectors)

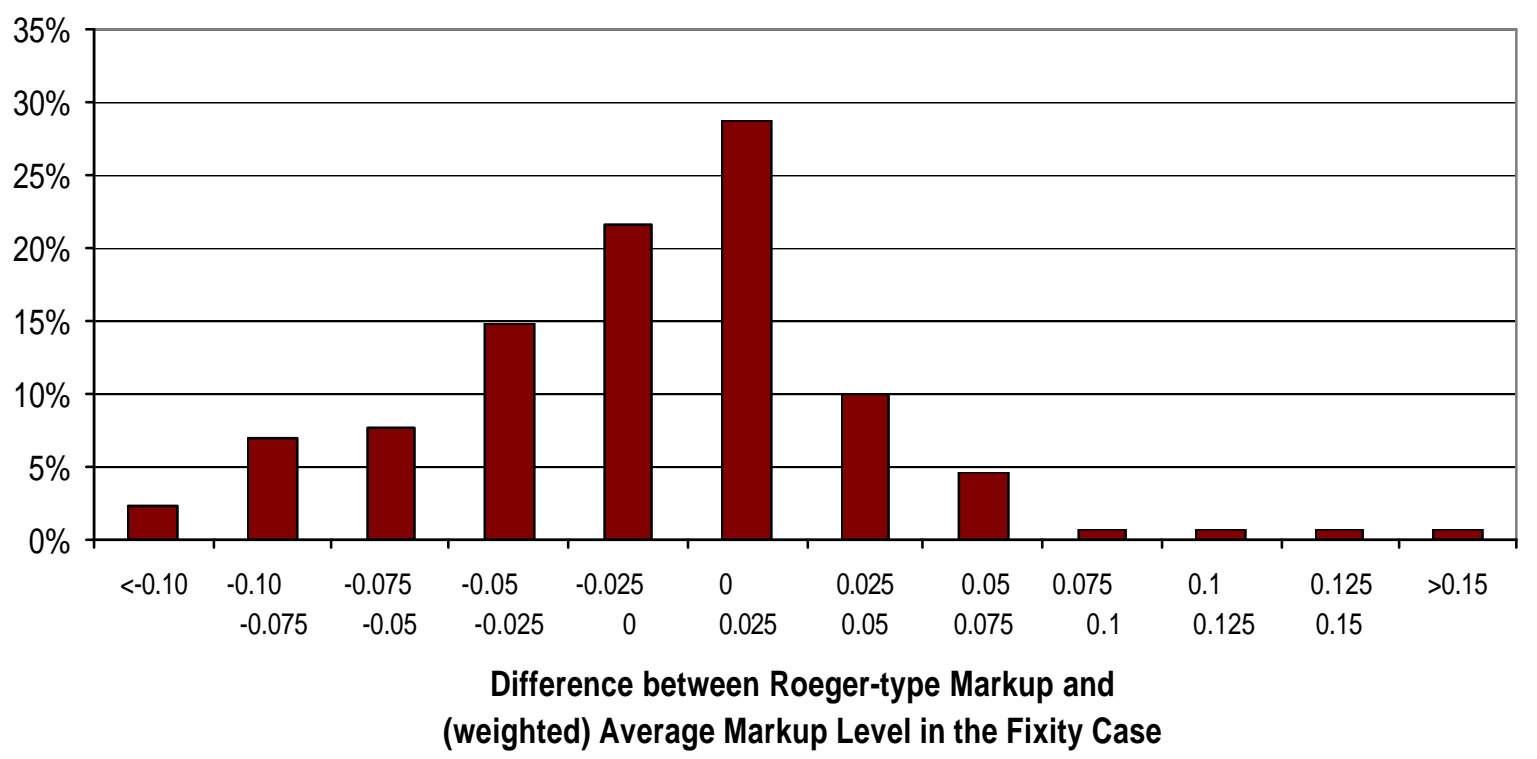


Figure 4

Comparison between Markup Estimates (see Table 4)

\section{USA two-digit Sectors}

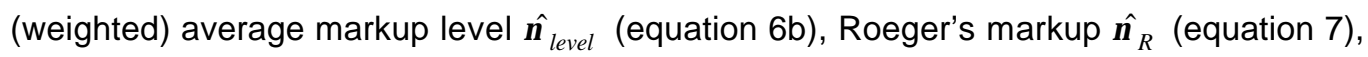

(weighted) average markup level in the fixity case $\hat{v}_{\text {fix }}^{\text {level }}$ (equation 10)

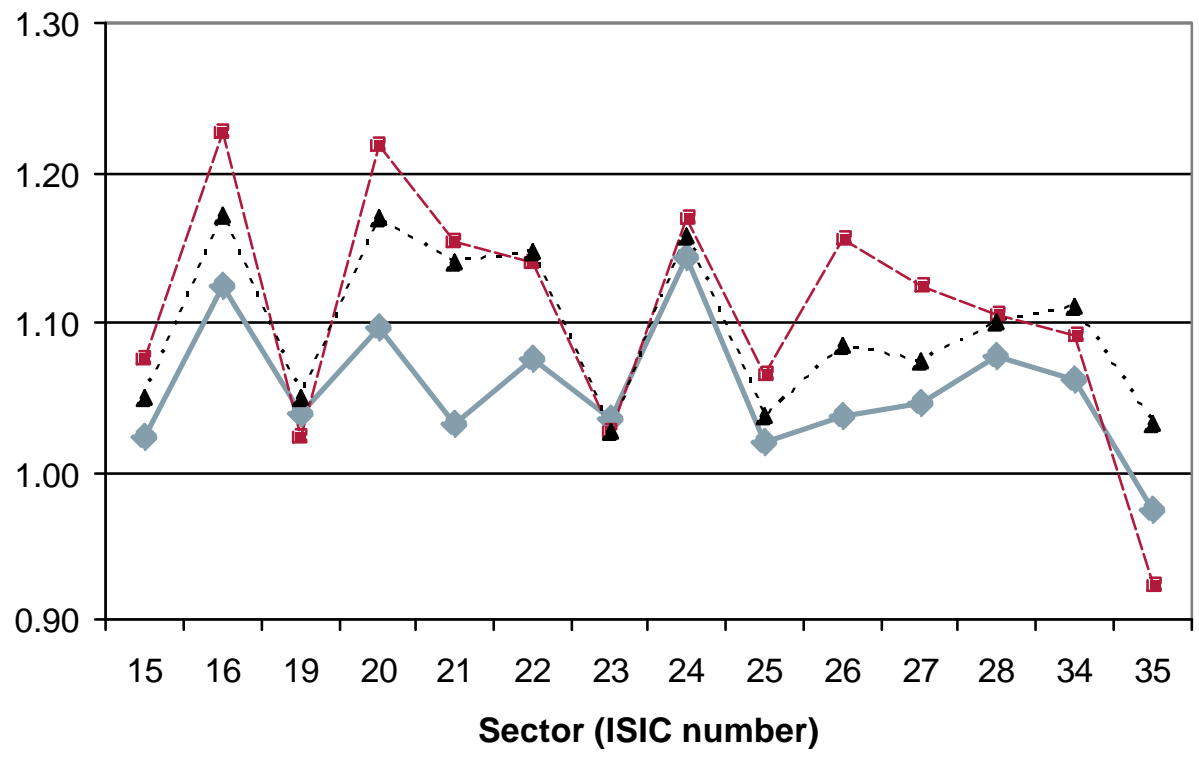

$--\uparrow-\infty$ (weighted) average markup level, eq. (6b)

--- Roeger's markup, eq. (7)

... . (weighted) average markup level in the fixity case, eq. (10) 
Table 1

Difference between Roeger's Markups and (weighted) Average Markup Levels

USA two-digit sectors, $1970-2000$

\begin{tabular}{|c|c|c|c|c|c|c|c|c|c|c|}
\hline \multirow[b]{2}{*}{ Country } & \multirow{2}{*}{\multicolumn{2}{|c|}{ ISIC Rev.3 }} & \multicolumn{2}{|c|}{$\begin{array}{l}\text { Level equation (6b) } \\
\text { (OLS) }\end{array}$} & \multicolumn{2}{|c|}{$\begin{array}{l}\text { Level equation (6b) } \\
\text { (AR2)* }\end{array}$} & \multicolumn{3}{|c|}{$\begin{array}{c}\text { Roeger's equation (7) } \\
\text { (OLS) }\end{array}$} & \multirow{2}{*}{$\begin{array}{c}\text { Roeger's } \\
\text { - level } \\
\text { diffe- } \\
\text { rence }\end{array}$} \\
\hline & & & $\hat{v}_{\text {level }}$ & $\begin{array}{l}\text { Durbin- } \\
\text { Watson }\end{array}$ & $\hat{v}_{\text {level }}$ & std & $\hat{v}_{R}$ & std & $\begin{array}{l}\text { Durbin- } \\
\text { Watson }\end{array}$ & \\
\hline usa & 15 & Food and Beverages & 1.057 & 0.408 & 1.024 & 0.051 & 1.076 & 0.020 & 2.399 & 0,052 \\
\hline usa & 16 & Tobacco & 1.130 & 0.970 & 1.124 & 0.029 & 1.227 & 0.041 & 1.667 & 0,103 \\
\hline usa & 19 & Leather and Footwear & 1.125 & 0.448 & 1.039 & 0.074 & 1.023 & 0.043 & 2.534 & $-0,016$ \\
\hline usa & 20 & Wood and Cork & 1.098 & 0.720 & 1.096 & 0.011 & 1.219 & 0.036 & 1.885 & 0,122 \\
\hline usa & 21 & Pulp and Paper & 1.031 & 0.900 & 1.032 & 0.009 & 1.154 & 0.031 & 1.835 & 0,122 \\
\hline usa & 22 & Printing and Publishing & 1.075 & 1.045 & 1.075 & 0.007 & 1.140 & 0.035 & 2.799 & 0,065 \\
\hline usa & 23 & Coke, Ref.Petrol., Nuclear Fuel & 1.041 & 0.615 & 1.037 & 0.018 & 1.026 & 0.033 & 2.194 & $-0,010$ \\
\hline usa & 24 & Chemicals & 1.126 & 0.133 & 1.143 & 0.040 & 1.169 & 0.032 & 1.438 & 0,026 \\
\hline usa & 25 & Rubber and Plastic & 1.018 & 0.606 & 1.019 & 0.011 & 1.065 & 0.018 & 2.464 & 0,046 \\
\hline usa & 26 & Other Non-Metallic Mineral & 1.022 & 0.296 & 1.038 & 0.034 & 1.155 & 0.028 & 2.167 & 0,117 \\
\hline usa & 27 & Basic Metals & 0.971 & 0.467 & 1.047 & 0.082 & 1.125 & 0.052 & 2.863 & 0,078 \\
\hline usa & 28 & Fabricated Metal & 1.080 & 0.162 & 1.078 & 0.013 & 1.105 & 0.021 & 1.263 & 0,027 \\
\hline usa & 34 & Motor Vehicles and Trailers & 1.040 & 0.283 & 1.062 & 0.024 & 1.091 & 0.073 & 1.824 & 0,029 \\
\hline usa & 35 & Other Transport Equipment & 0.973 & 1.027 & 0.974 & 0.007 & 0.925 & 0.096 & 2.326 & $-0,048$ \\
\hline $\mathrm{me}$ & & & 1.056 & & 1.056 & 0.029 & 1.107 & 0.040 & & 0.051 \\
\hline
\end{tabular}

$\left(^{*}\right)$ : Estimates are produced from an $A R(2)$ process for the residuals, which corrects for auto-correlation successfully. Standard deviations are robust to heteroscedasticity and autocorrelation.

Equation (6b): $\quad P . Y=v_{\text {level }} .(R \cdot K+W \cdot L+Q \cdot M)$

Equation (7) : $\quad d p y-d r k=v_{R} \cdot\left[a_{L} \cdot(d w l-d r k)+a_{M} \cdot(d q m-d r k)\right]$ 
Table 2

Robustness of the Difference across Different Measures of Capital Services and Cost ${ }^{\star}$

USA two-digit sectors, $1970-2000$

\begin{tabular}{|c|c|c|c|c|c|c|c|c|c|c|c|c|c|}
\hline & \multirow[b]{2}{*}{ sector } & \multicolumn{4}{|c|}{$\begin{array}{c}\text { Level equation markup estimates } \\
\qquad \hat{v}_{\text {level }}\end{array}$} & \multicolumn{4}{|c|}{$\begin{array}{c}\text { Difference (Roeger's-level) } \\
\qquad \hat{v}_{R}-\hat{v}_{\text {level }}\end{array}$} & \multicolumn{4}{|c|}{ Average capital share of output } \\
\hline & & $\overline{\mathrm{K} 1}$ & $\mathrm{~K} 2$ & $\overline{\mathrm{K} 3}$ & $\overline{\mathrm{K} 4}$ & $\overline{\mathrm{K} 1}$ & $\overline{\mathrm{K} 2}$ & $\overline{\mathrm{K} 3}$ & $\overline{\mathrm{K} 4}$ & $\overline{\mathrm{K} 1}$ & $\mathrm{~K} 2$ & $\overline{\mathrm{K} 3}$ & $\overline{\mathrm{K} 4}$ \\
\hline usa & 15 & 1.024 & 1.025 & 1.028 & 1.039 & 0.052 & 0.046 & 0.076 & 0.067 & 0.041 & 0.037 & 0.065 & 0.056 \\
\hline usa & 16 & 1.124 & 1.285 & 1.090 & 1.103 & 0.103 & -0.056 & 0.162 & 0.150 & 0.038 & 0.035 & 0.066 & 0.056 \\
\hline usa & 19 & 1.039 & 1.038 & 1.053 & 1.072 & -0.016 & -0.034 & 0.086 & 0.069 & 0.036 & 0.031 & 0.093 & 0.078 \\
\hline usa & 20 & 1.096 & 1.106 & 1.029 & 1.048 & 0.122 & 0.127 & 0.165 & 0.150 & 0.059 & 0.053 & 0.108 & 0.094 \\
\hline usa & 21 & 1.032 & 1.038 & 1.015 & 1.031 & 0.122 & 0.127 & 0.105 & 0.089 & 0.086 & 0.081 & 0.095 & 0.082 \\
\hline usa & 22 & 1.075 & 1.079 & 1.078 & 1.090 & 0.065 & 0.050 & 0.027 & 0.013 & 0.053 & 0.049 & 0.062 & 0.052 \\
\hline usa & 23 & 1.037 & 1.039 & 1.030 & 1.038 & -0.010 & -0.017 & 0.045 & 0.037 & 0.049 & 0.045 & 0.056 & 0.048 \\
\hline usa & 24 & 1.143 & 1.147 & 1.046 & 1.076 & 0.026 & 0.022 & 0.123 & 0.092 & 0.085 & 0.078 & 0.140 & 0.119 \\
\hline usa & 25 & 1.019 & 1.022 & 1.015 & 1.025 & 0.046 & 0.038 & 0.020 & -0.001 & 0.059 & 0.056 & 0.056 & 0.048 \\
\hline usa & 26 & 1.038 & 1.050 & 1.027 & 1.044 & 0.117 & 0.115 & 0.117 & 0.102 & 0.085 & 0.077 & 0.084 & 0.072 \\
\hline usa & 27 & 1.047 & 1.055 & 1.000 & 1.009 & 0.078 & 0.080 & 0.045 & 0.034 & 0.098 & 0.082 & 0.073 & 0.063 \\
\hline usa & 28 & 1.078 & 1.083 & 1.040 & 1.056 & 0.027 & 0.019 & 0.064 & 0.046 & 0.052 & 0.047 & 0.082 & 0.069 \\
\hline usa & 34 & 1.062 & 1.065 & 1.019 & 1.042 & 0.029 & 0.033 & 0.055 & 0.035 & 0.056 & 0.050 & 0.158 & 0.136 \\
\hline usa & 35 & 0.974 & 0.979 & 1.003 & 1.008 & -0.048 & -0.083 & 0.018 & 0.013 & 0.057 & 0.050 & 0.030 & 0.025 \\
\hline \multicolumn{2}{|l|}{ mean } & 1.056 & 1.072 & 1.034 & 1.049 & 0.051 & 0.034 & 0.079 & 0.064 & 0.061 & 0.055 & 0.083 & 0.071 \\
\hline \multicolumn{6}{|c|}{ difference / capital share correlation } & 0.40 & 0.62 & 0.42 & 0.34 & & & & \\
\hline
\end{tabular}

(*) Capital variables are described in the Appendix. Sector description is given in Table 1.

\section{Note}

The last row of the table computes the linear correlation coefficient between the difference in the estimates $\hat{v_{R}}-\hat{v}_{\text {level }}$ (second part of the table) and the average capital share from the data, for each capital series respectively. The distinct positive correlation is consistent with the theoretical relationship found when capital is fixed in the Cobb-Douglas case (at the end of Section 4), whereby the difference is positively related to $a$, the long term capital share in total cost. 
Table 3

Implied Capital Shares from $a_{K}=1 / \hat{v}-a_{L}-a_{M}$

USA two-digit sectors, $1970-2000$

\begin{tabular}{|c|c|c|c|c|c|c|c|c|c|c|c|c|}
\hline & & & \multicolumn{5}{|c|}{ Capital computation : K1 } & \multicolumn{5}{|c|}{ Capital computation : K3 } \\
\hline & & $\begin{array}{l}\text { Frequency } \\
\text { of Labor } \\
\text { +Materials } \\
\text { shares } \\
\text { greater } \\
\text { than } 1\end{array}$ & \multicolumn{2}{|c|}{$\begin{array}{c}\text { Frequency of } \\
\text { negative implied } \\
\text { capital share }\end{array}$} & \multicolumn{3}{|c|}{ Average capital share } & \multicolumn{2}{|c|}{$\begin{array}{c}\text { Frequency of } \\
\text { negative implied } \\
\text { capital share }\end{array}$} & \multicolumn{3}{|c|}{ Average capital share } \\
\hline $\begin{array}{c}\text { Coun- } \\
\text { try }\end{array}$ & $\begin{array}{c}\text { Sec- } \\
\text { tor }\end{array}$ & data & $\begin{array}{l}\hat{\text { level }} \\
\hat{v}_{\text {level }}\end{array}$ & $\begin{array}{c}\overline{\text { Roeger }} \\
\hat{\mathrm{v}}_{R}\end{array}$ & data & level & Roeger & level & Roeger & data & level & Roeger \\
\hline usa & 15 & 0.00 & 0.00 & 0.21 & 0.041 & 0.066 & 0.018 & 0.00 & 0.52 & 0.065 & 0.062 & -0.004 \\
\hline usa & 16 & 0.00 & 0.04 & 0.71 & 0.038 & 0.069 & -0.006 & 0.00 & 0.78 & 0.066 & 0.097 & -0.024 \\
\hline usa & 19 & 0.00 & 0.00 & 0.00 & 0.036 & 0.112 & 0.126 & 0.00 & 0.39 & 0.093 & 0.099 & 0.030 \\
\hline usa & 20 & 0.00 & 0.00 & 0.87 & 0.059 & 0.063 & -0.029 & 0.00 & 0.73 & 0.108 & 0.122 & -0.012 \\
\hline usa & 21 & 0.00 & 0.00 & 0.83 & 0.086 & 0.083 & -0.020 & 0.00 & 0.39 & 0.095 & 0.099 & 0.007 \\
\hline usa & 22 & 0.00 & 0.00 & 0.25 & 0.053 & 0.060 & 0.007 & 0.00 & 0.00 & 0.062 & 0.058 & 0.034 \\
\hline usa & 23 & 0.00 & 0.08 & 0.00 & 0.049 & 0.057 & 0.067 & 0.00 & 0.35 & 0.056 & 0.064 & 0.026 \\
\hline usa & 24 & 0.00 & 0.04 & 0.42 & 0.085 & 0.050 & 0.030 & 0.00 & 0.39 & 0.140 & 0.130 & 0.031 \\
\hline usa & 25 & 0.00 & 0.00 & 0.13 & 0.059 & 0.054 & 0.012 & 0.00 & 0.00 & 0.056 & 0.058 & 0.039 \\
\hline usa & 26 & 0.00 & 0.03 & 0.87 & 0.085 & 0.066 & -0.032 & 0.03 & 0.77 & 0.084 & 0.076 & -0.024 \\
\hline usa & 27 & 0.00 & 0.17 & 1.00 & 0.098 & 0.019 & -0.047 & 0.00 & 0.13 & 0.073 & 0.063 & 0.020 \\
\hline usa & 28 & 0.00 & 0.00 & 0.29 & 0.052 & 0.045 & 0.023 & 0.00 & 0.26 & 0.082 & 0.079 & 0.024 \\
\hline usa & 34 & 0.00 & 0.21 & 0.42 & 0.056 & 0.020 & -0.004 & 0.04 & 0.35 & 0.158 & 0.061 & 0.009 \\
\hline usa & 35 & 0.21 & 0.13 & 0.04 & 0.057 & 0.047 & 0.101 & 0.21 & 0.26 & 0.030 & 0.017 & 0.000 \\
\hline mean & & 0.015 & 0.050 & 0.430 & 0.061 & 0.058 & 0.018 & 0.020 & 0.380 & 0.083 & 0.077 & 0.011 \\
\hline
\end{tabular}


Table 4

Blunt Test of the Capital Fixity Assumption

$P . Y=v \cdot(W \cdot L+Q \cdot M)+h v \cdot R \cdot K+u$

\begin{tabular}{|c|c|c|c|c|c|c|c|c|c|c|c|}
\hline \multirow[b]{2}{*}{ country } & \multirow[b]{2}{*}{ sector } & \multirow{2}{*}{$\begin{array}{c}\text { level } \\
\text { AR(2) } \\
h=1 \\
(1) \\
\hat{v}_{\text {level }}\end{array}$} & \multirow{2}{*}{$\begin{array}{c}\text { Roeger' } \\
\mathrm{S} \\
(2) \\
\hat{v}_{R}\end{array}$} & \multicolumn{2}{|c|}{$\begin{array}{c}\text { level } \\
\text { AR(2) } \\
h=0 \\
\text { (3) }\end{array}$} & \multicolumn{3}{|c|}{$\begin{array}{c}\text { level } \\
\mathrm{AR}(2) \\
0<h<1 \\
\text { (4) }\end{array}$} & \multicolumn{3}{|c|}{$\begin{array}{c}\text { level } \\
\mathrm{AR}(2) \\
\text { unbounded } h \\
\text { (5) }\end{array}$} \\
\hline & & & & $\hat{\mathrm{v}}_{\text {level }}^{f i x}$ & s.d. & $v$ & $h$ & s.d. (h) & $v$ & $h$ & s.d. (h) \\
\hline usa & 15 & 1.024 & 1.076 & 1.049 & 0.048 & 1.043 & 0.25 & 0.37 & 1.043 & 0.25 & 0.37 \\
\hline usa & 16 & 1.124 & 1.227 & 1.171 & 0.054 & 1.145 & 0.57 & 1.10 & 1.145 & 0.57 & 1.10 \\
\hline usa & 19 & 1.039 & 1.023 & 1.050 & 0.076 & 1.039 & 1.00 & 0.00 & 1.037 & 1.26 & 1.56 \\
\hline usa & 20 & 1.096 & 1.219 & 1.170 & 0.014 & 1.170 & 0.00 & 0.00 & 1.187 & -0.22 & 0.39 \\
\hline usa & 21 & 1.032 & 1.154 & 1.141 & 0.010 & 1.140 & 0.00 & 0.00 & 1.180 & -0.33 & 0.22 \\
\hline usa & 22 & 1.075 & 1.140 & 1.146 & 0.005 & 1.141 & 0.07 & 0.51 & 1.141 & 0.07 & 0.51 \\
\hline usa & 23 & 1.037 & 1.026 & 1.027 & 0.027 & 1.027 & 0.00 & 0.00 & 1.042 & -0.93 & 0.84 \\
\hline usa & 24 & 1.143 & 1.169 & 1.158 & 0.049 & 1.149 & 0.18 & 0.35 & 1.149 & 0.18 & 0.35 \\
\hline usa & 25 & 1.019 & 1.065 & 1.038 & 0.038 & 1.029 & 0.20 & 0.32 & 1.029 & 0.20 & 0.32 \\
\hline usa & 26 & 1.038 & 1.155 & 1.084 & 0.064 & 1.084 & 0.00 & 0.00 & 1.098 & -0.21 & 0.37 \\
\hline usa & 27 & 1.047 & 1.125 & 1.073 & 0.016 & 1.073 & 0.00 & 0.00 & 1.123 & -0.44 & 0.09 \\
\hline usa & 28 & 1.078 & 1.105 & 1.100 & 0.021 & 1.080 & 0.96 & 0.33 & 1.080 & 0.96 & 0.33 \\
\hline usa & 34 & 1.062 & 1.091 & 1.110 & 0.018 & 1.081 & 0.56 & 0.60 & 1.081 & 0.56 & 0.60 \\
\hline usa & 35 & 0.974 & 0.925 & 1.032 & 0.009 & 0.974 & 1.00 & 0.00 & 0.932 & 1.79 & 1.05 \\
\hline & & 1.056 & 1.107 & 1.096 & 0.032 & 1.084 & 0.34 & & 1.091 & 0.22 & \\
\hline
\end{tabular}


Table 5

Formal Tests:

Number of sectors for which the equality of the parameters can be rejected

out of the 129 (country $x$ sector) time series

\begin{tabular}{l|c|c|c}
\hline Null Hypothesis & \multicolumn{3}{|c}{ Significance level } \\
$H 0$ & $1 \%$ & $5 \%$ & $10 \%$ \\
\hline$v_{\text {level }}=v_{R}$ & 56 & 78 & 89 \\
$v_{\text {level }}^{f i x}=v_{R}^{f i x}$ & 9 & 18 & 25 \\
$v_{R}=v_{R}^{f i x}$ & 0 & 4 & 13 \\
$v_{\text {level }}^{f i x}=v_{R}$ & 5 & 14 & 15 \\
$v_{\text {level }}^{f i x}=v_{\text {level }}$ & 76 & 89 & 96 \\
\hline
\end{tabular}

$\left.{ }^{*}\right)$ :Standard deviationsused are robust to heteroscedasticity and autocorrelation.

Equations

$$
\begin{aligned}
& P . Y=\mathrm{v}_{\text {level }} \cdot(R \cdot K+W \cdot L+Q \cdot M) \\
& d p y-d r k=\mathrm{v}_{R} \cdot\left[a_{L} \cdot(d w l-d r k)+a_{M} \cdot(d q m-d r k)\right] \\
& P . Y=v_{\text {level }}^{f i x} \cdot(W \cdot L+Q \cdot M) \\
& d p y=v_{R}^{f i x} \cdot\left[a_{L} \cdot d w l+a_{M} \cdot d q m\right]
\end{aligned}
$$

Reading: The null hypothesis that the markup estimated from the equation in level (6b) equals the markup estimated from the price-based equation (7) is rejected in 78 sectors out of the 129 in the sample at the $5 \%$ significance level. 
Table A1: ISIC Rev. 3 Classification

\begin{tabular}{|c|c|c|c|}
\hline & Sector desrciption & & More aggregated sample \\
\hline 15 & FOOD PRODUCTS AND BEVERAGES & $15-16$ & $\begin{array}{l}\text { FOOD PRODUCTS, BEVERAGES AND } \\
\text { TOBACCO }\end{array}$ \\
\hline 16 & TOBACCO PRODUCTS & $17-19$ & $\begin{array}{l}\text { TEXTILES, TEXTILE PRODUCTS, LEATHER AND } \\
\text { FOOTWEAR }\end{array}$ \\
\hline 17 & TEXTILES & 20 & WOOD AND PRODUCTS OF WOOD AND CORK \\
\hline 18 & WEARING APPAREL, DRESSING, DYING OF FUR & $21-22$ & $\begin{array}{l}\text { PULP, PAPER, PAPER PRODUCTS, PRINTING } \\
\text { AND PUBLISHING }\end{array}$ \\
\hline 19 & $\begin{array}{l}\text { LEATHER, LEATHER PRODUCTS AND } \\
\text { FOOTWEAR }\end{array}$ & $23-25$ & $\begin{array}{l}\text { CHEMICAL, RUBBER, PLASTICS AND FUEL } \\
\text { PRODUCTS }\end{array}$ \\
\hline 20 & WOOD AND PRODUCTS OF WOOD AND CORK & & OTHER NON-METALLIC MINERAL PRODUCTS \\
\hline 21 & PULP, PAPER AND PAPER PRODUCTS & $27-28$ & $\begin{array}{l}\text { BASIC METALS AND FABRICATED METAL } \\
\text { PRODUCTS }\end{array}$ \\
\hline 22 & PRINTING AND PUBLISHING & & MACHINERY AND EQUIPMENT, N.E.C. \\
\hline 23 & $\begin{array}{l}\text { COKE, REFINED PETROLEUM PRODUCTS AND } \\
\text { NUCLEAR FUEL }\end{array}$ & $30-33$ & ELECTRICAL AND OPTICAL EQUIPMENT \\
\hline 24 & CHEMICALS AND CHEMICAL PRODUCTS & $34-35$ & TRANSPORT EQUIPMENT \\
\hline 25 & RUBBER AND PLASTICS PRODUCTS & $36-37$ & MANUFACTURING NEC; RECYCLING \\
\hline 26 & OTHER NON-METALLIC MINERAL PRODUCTS & & \\
\hline 27 & BASIC METALS & & \\
\hline 28 & $\begin{array}{l}\text { FABRICATED METAL PRODUCTS, except } \\
\text { machinery and equipment }\end{array}$ & & \\
\hline 29 & MACHINERY AND EQUIPMENT, N.E.C. & & \\
\hline 30 & $\begin{array}{l}\text { OFFICE, ACCOUNTING AND COMPUTING } \\
\text { MACHINERY }\end{array}$ & & \\
\hline 31 & $\begin{array}{l}\text { ELECTRICAL MACHINERY AND APPARATUS, } \\
\text { NEC }\end{array}$ & & \\
\hline 32 & $\begin{array}{l}\text { RADIO, TELEVISION AND COMMUNICATION } \\
\text { EQUIPMENT }\end{array}$ & & \\
\hline 33 & $\begin{array}{l}\text { MEDICAL, PRECISION AND OPTICAL } \\
\text { INSTRUMENTS }\end{array}$ & & \\
\hline 34 & $\begin{array}{l}\text { MOTOR VEHICLES, TRAILERS AND SEMF- } \\
\text { TRAILERS }\end{array}$ & & \\
\hline 35 & OTHER TRANSPORT EQUIPMENT & & \\
\hline 36 & MANUFACTURING NEC & & \\
\hline 37 & RECYCLING & & \\
\hline
\end{tabular}

Table A2: Computation of initial capital stock for each sector: Average over time and countries (Belgium, Canada, Finland, France and Italy) of $p_{k} . C A P K / V A L U$

\begin{tabular}{c|c}
\hline sector & $\chi$ \\
\hline $15-16$ & 2.75 \\
\hline $17-19$ & 2.07 \\
\hline 20 & 3.91 \\
\hline $21-22$ & 2.89 \\
\hline $23-25$ & 3.31 \\
\hline 26 & 3.15 \\
\hline $27-28$ & 3.14 \\
\hline 29 & 1.52 \\
\hline $30-33$ & 1.52 \\
\hline $34-35$ & 2.39 \\
\hline $36-37$ & 2.55 \\
\hline
\end{tabular}

